\title{
Increasing Trend of Mortality and Cost of Infectious Disease in Republic of Korea
}

\section{- Trend of Mortality and Cost of Infectious Disease -}

Dahye Baik, Byung-Woo Kim, Moran Ki*

Graduate School of Cancer Science and Policy, National Cancer Center, Goyang, Republic of Korea

Dahye Baik: https://orcid.org/0000-0002-7112-3740

Byung-Woo Kim: https://orcid.org/0000-0003-4986-1162

Moran Ki: https://orcid.org/0000-0002-8892-7104

*Corresponding author: Moran Ki, MD, PhD

Department of Cancer Control and Population health, Graduate School of Cancer Science and Policy, National Cancer Center, Republic of Korea

323 Ilsan-ro, Ilsandong-gu, Goyang-si, Gyeonggi-do. 10408

Tel: $+82-31-920-2736$

E-mail: moranki@ncc.re.kr

This work was supported by a grant from the National Cancer Center (NCC-2010200). 


\section{Abstract}

Objectives: Republic of Korea is still endangered by outbreak of infectious diseases that causes great burdens on health care system, although average life expectancy and overall mortality rate tended to improve. This study identifies the trends of changes in mortality and economic burden of infectious diseases.

Methods: Data from health care statistics of the Health Insurance Review and Assessment Service (2009-2019) and Korean Statistics Information Service (1997-2019) were used. We selected 10 infectious disease groups (intestinal infections, tuberculosis, vaccine-preventable diseases, sepsis, viral hepatitis, HIV-related diseases, central nervous system infections, rheumatic heart diseases, respiratory tract infections and arthropod-borne viral diseases).

Results: The age-standardized mortality rate for infectious diseases increased from 27.2 per 100,000 population in 1997 to 37.1 per 100,000 population in 2019 and had upward trend since 2004. It had significant increase in respiratory tract infections and among elderly persons especially, age $\geq 85$ years during the same period. The costs for infectious diseases increased to 6,612 million USD in 2019 from 4,126 million USD in 2009. The largest proportion of the costs was observed in respiratory tract infections as 3,699 million USD in 2019 (69\%). The annual cost per patient who visited hospital for infectious diseases increased from 131 USD in 2009 to 204 USD in 2019.

Conclusions: The mortality rate among elderly persons and persons with respiratory tract infections tended to increase during study period. The economic burden of infectious diseases has consistently increased, especially in respiratory tract infections. It is therefore essential to establish an effective management policy considering particular infectious diseases and patient group.

\section{Keywords}

Infectious diseases, Mortality, Cost of Illness, trends, Republic of Korea

\section{Introduction}

After industrialization, deaths caused by infectious disease have decreased in many developed countries due to improvements in hygiene, introduction of vaccination and antimicrobial therapy (1). However, the epidemiology of infectious diseases has been complicated by socio-demographic index, and further, infectious diseases still represent a considerable number of deaths globally (2). 
Over the past few decades, average life expectancy and overall mortality rate tended to improve in Republic of Korea (hereafter referred to as Korea) affected by rapid economic growth. The overall crude mortality rate reduced substantially from 6.4 deaths per 1,000 population in 1983 to 5.7 per 1,000 in 2019, as rising average life expectancy from 67.5 years in 1983 to 83.2 years in $2019(3,4)$. However, Korea is still endangered by outbreak of emerging infectious diseases that causes great burdens on healthcare system: Severe Acute Respiratory Syndrome (SARS) in 2002-2003, H1N1 Influenza in 2009, Middle East Respiratory Syndrome (MERS) in 2015, and ongoing outbreak of Coronavirus disease 2019 (COVID-19) (5). Moreover, some infectious diseases such as hepatitis B or $C$ virus and human papilloma virus affect the incidence of chronic diseases (e.g., cancer). With the rise in chronic diseases, most healthcare policies and financial resources have currently focused on the management of non-communicable diseases in Korea (5). Thus, effective intervention strategies for managing infectious diseases are needed as exploring changes of infectious diseases epidemiology.

Cost of illness (COI) study is considered to be an essential measurement technique for evaluating socio-economic impacts associated with diseases. It can help healthcare decision-makers to determine and prioritize healthcare policies and interventions as good baseline measure to identify the efficacy of health policies or intervention strategies (6). Research on cost of infectious disease has primarily focused on specific diseases like hepatitis $B$ and respiratory disease $(7,8)$. Moreover, previous studies focused on disability-adjusted life years for communicable disease (5) and mortality trend of infectious disease $(1,9)$. Research encompassing overall infectious disease is scarce and research concerning both mortality and COI of overall infectious disease has never been conducted in Korea. Therefore, this study aims to suggest priorities for evidence-informed policy making to control infectious disease effectively by identifying the trends of changes in mortality and economic burden of infectious disease.

\section{Methods}

Data from the national death certificate and the population census of Korean Statistics Information Service (KOSIS) from 1997 to 2019 and health care statistics of the Health Insurance Review and Assessment Service (HIRA) between 2009 and 2019 were used. In Korea, the National Health Insurance Service (NHIS) is a mandatory insurance and $97 \%$ of the population is enrolled in the National Health Insurance program $(7,10)$. Moreover, its data include the information regarding claims for reimbursed medical services which contain details of diseases and bills, records on 
inpatient and outpatient usage (diagnosis, length of stay, treatment costs) and prescription records (drug code, days prescribed, daily dosage), classified according to disease diagnosis (11).

Cases of infectious disease were selected based on a primary diagnosis and confirmed when inpatient and outpatient claims occurred at least once over the course of one year. With reference to the previous study (1), those cases were classified by 10 disease groups (Table 1 ). The international Statistical Classification of Disease and Related Health Problems 10th Revision [ICD-10] code was used to identify each infectious disease.

The mortality rate was defined as the annual number of deaths caused by (all or each) infectious disease, based on the cause of death data from KOSIS, divided by the total population, using KOSIS data on sex and age. The prevalence rate was defined as the number of patients who were treated for infectious disease each year. It considered the annual total number of infectious disease cases from HIRA data, divided by the total registered population. Age-standardized mortality rate (ASMR) and age-standardized prevalence rate (ASPR) were adjusted using registered population data in 2010. Both rates are shown as the rate per 100,000 people. To identify the trend of mortality rate, the Average Percent Change (APC) analyses were performed using the Joinpoint Regression Program V.4.8.0.1 (12).

Costs of infectious disease were estimated using a prevalence-based approach which estimates the economic burden of a condition over a specific period, usually a year (6). It measured the total cost with treating infectious diseases among both pre-existing and newly diagnosed patients paid annually, regardless of the number of visits to the hospital by the same patient. This study considered direct healthcare costs as the total healthcare cost including detailed healthcare utilization, prescribed drugs and medical costs. The costs were calculated by the sum of medical costs paid by inpatients and outpatients at medical institutions and pharmacies. In this study, 1 US dollar (USD) equaled 1136.7 Korean won (KRW) as the currency exchange rate was determined by the average exchange rate between 2009 and 2019 (13). To eliminate the effects of inflation, annual costs were adjusted based on the 2015 costs using the Korean Consumer Price Index data by expenditure category of health (14).

\section{Results}

The overall ASMR in Korea has had a negative slope from 829.3 per 100,000 population in 1997 to 378.9 per 100,000 population in 2019 (APC $-3.5, p<0.05$ ). Nevertheless, the number of deaths caused 
by infectious disease increased from 8,292 in 1997 to 33,600 in 2019. The ASMR of all infectious diseases increased from 27.2 per 100,000 population in 1997 to 37.1 per 100,000 population in 2000 (APC 7.43), but then declined annually by $8.2 \%(p<0.05)$ to 26.0 per 100,000 population in 2004 (Figure 1). After 2004, it gradually increased to 39.0 per 100,000 population in 2019 (APC 3.26, $p<0.05)$. Though the ASPR of all infectious diseases fluctuated annually, it exhibited upward trend from 63,429 per 100,000 population in 2009 to 64,359 per 100,000 population in 2019 . The average annual percent change (AAPC) was $1.6 \%$ in $\operatorname{ASMR}(p<0.05)$ and $0.4 \%$ in ASPR $(p<0.05)$.

In 1997, tuberculosis was the leading cause of infectious disease deaths; the ASMR was 11.5 per 100,000 population (Figure 2). However, the ASMR from tuberculosis gradually declined since 1997; it was 1.9 per 100,000 population in 2019 (AAPC -7.7, p<0.05) (Supplementary 1). Respiratory tract infections were the leading cause of infectious disease deaths from 1998. Moreover, there was a dramatic rise in ASMR from respiratory tract infections which was 9.2 per 100,000 population in 1997 and it increased to 27.0 per 100,000 population in 2019 (AAPC 5.2, $p<0.05$ ) (Figure 2, Supplementary 1). The ASMR from sepsis showed increasing trend since 2003 and sepsis was second leading cause of infectious disease deaths from 2014. The ASMR from central nervous system infections was 0.7 per 100,000 population followed by intestinal infections and viral hepatitis $(0.6$ per 100,000 population) in 1997. However, viral hepatitis was the fourth leading cause of infectious disease deaths; the ASMR from viral hepatitis was 2.0 per 100,000 population in 2015 followed by intestinal infections (1.0 per 100,000 population) and central nervous system infections (0.4 per 100,000 population). The rank between ASMR from viral hepatitis and intestinal infections was finally reversed since 2016.

The ASPR from respiratory tract infections was highest among 10 disease groups during the study period (2009-2019). Annually, average 54,449 of 100,000 population were diagnosed by respiratory tract infections (Supplementary 2). Intestinal infections were second most diagnosis of infectious disease among 10 disease groups followed by viral hepatitis. As the ASPR from tuberculosis dramatically decreased, it declined from 235.9 per 100,000 population in 2009 to 86.8 per 100,000 population in 2019.

With regard to respiratory tract infection, the age-specific mortality rate has had significant difference between the age groups (Figure 3). Whereas the mortality in young age, 0-14 age group decreased during the study period (1997-2019), the mortality in old age, consistently increased. Especially, the mortality in $\geq 85$ years, increased dramatically from 251.6 per 100,000 population in 1997 to 1,550 per 100,000 population in 2019 . 
The total healthcare costs of infectious disease showed upward trend during the study period (20092019) in Korea (Figure 4). It was 4,126 million USD in 2009 including the extra-hospital pharmaceutical cost (1,064 million USD). In 2019, it was 1.6 times higher at 6,612 million USD including the extra-pharmaceutical cost (1,303 million USD). Likewise, the inflation adjusted total costs have increased during the period.

The total healthcare cost from respiratory tract infection was the highest among 10 disease groups during the study period (2009-2019). It was 2,606 million USD in 2009, and it was 1.4 times higher in 2019 at 3,699 million USD (Figure 5). In 2009, viral hepatitis was ranked the second highest medical cost of 10 disease groups followed by intestinal infections. Conversely, the cost from intestinal infections reversed the rank followed by the cost from viral hepatitis in 2019. Costs from the other disease groups have increasing trend. Among those groups, the costs from HIV-related diseases had the highest rate of increase during the period. It was 27.4 million USD in 2009, and it was 3.8 times greater than that of 2019 (103.3 million USD).

The number of patients who were treated for infectious disease were $31,570,316$ population in 2009, and it increased to 32,374,393 population in 2019 (Table 2). The healthcare cost per patient was 131 USD in 2009, and it was 1.6 times higher in 2019 at 204 USD. Taking in to account the effect of inflation, both total healthcare costs and average costs per patient have increased during the same period. Regarding inpatient and outpatient from infectious disease, both the number of patients and average cost per patient have increased from 2009 to 2019. The average days of hospitalization were 9 days and the average days of visit were 5.3 days during the study period (2009-2019).

\section{Discussion}

This study analyzed the trend of mortality and healthcare costs for total infectious disease in Korea, using nationally representative KOSIS data and NHIS data from HIRA. Though the ASMR from allcause deaths have declined, the ASMR and ASPR of infectious disease have upward trend (AAPC 1.6, $p<0.05$; AAPC $0.4, p<0.05$, respectively). Also, the healthcare cost of infectious disease showed positive slope.

The ASMR from respiratory tract infections was about 3 times higher during the study period. In 1997, respiratory tract infectious accounted for $34 \%$ of deaths caused by infectious disease. As it accounted for $69 \%$ in 2019, the proportion was 2 times higher than that of 1997 . It was primarily attributed to pneumonia and it was remarkable in old age, especially more than 85 age groups. 
Though the ASPR from sepsis decreased slowly, the ASMR from sepsis have increased since 2003. It suggests that respiratory tract infections particularly, pneumonia and sepsis become leading causes of death with rapid increase of ageing population in Korea.

Whereas the ASMR and ASPR from tuberculosis consistently declined, Korea was reported as the country with the highest incidence and the second highest mortality rate among the 36 OECD (Organization for Economic Co-operation and Development) countries in 2019 (15). Also, the healthcare cost caused by treating tuberculosis have increased. Though the ASMR from viral hepatitis was not high: average 1.5 per 100,000 population (1997-2019), the ASPR from viral hepatitis was third most diagnosis of infectious disease among 10 disease groups: average 880.7 per 100,000 population (2009-2019). This resulted in rise of healthcare cost mainly due to use of antiviral drugs (7). Moreover, related chronic diseases caused by viral hepatitis have considerably occurred. It suggests that tuberculosis and viral hepatitis, especially hepatitis $B$ and $C$ infection still remained a heavy burden on Korea.

Annually, about $63.4 \%$ of Korean visit hospital to treat infectious disease from 2009 to 2019. Most of them are outpatient and average $3.6 \%$ of the patients are inpatient. Both outpatient and inpatient accounted for about 3.2\% of total patient from infectious disease during the study period. Average days of hospitalization have decreased and those of visit have slowly declined toward the study period. However, total cost and average cost per patient caused by infectious disease showed upward trend. It demonstrates that the financial burden of healthcare cost for treating and managing infectious disease patients significantly increased in Korea.

This study has a few significant strengths. This study used NHIS claims data which are representative of the nationwide population. Therefore, its results represent the whole patients' data from infectious disease in Korea. Moreover, this study identified the cost of infectious disease for the first time in Korea. These findings should be used as the important reference for estimating the status of burden of infectious disease before COVID-19 outbreak in Korea. In 2019, the total paid medical expenditure from HIRA report was 75,684 million USD (16). Of this, the health care cost for infectious disease accounted for $8.7 \%$ and the proportion was lower than that of 2009 (11.9\%). However, it could not be concluded that the burden of infectious disease has been decreased because of the annual changes in total paid medical expenditure. These changes are resulted from the annual changes in policy of reimbursement and increasing aging population, etc. It is difficult to calculate the exact proportion of burden infectious disease, but the trend of proportion would be changed after COVID19 outbreak. This study would be the important reference for comparing the changes of epidemiology and burden of infectious disease before and after the outbreak of COVID-19. Further 
study should consider the mortality and cost of infectious disease on post corona since 2020.

However, there are some limitations to this study. First, the costs are likely underestimated because this study considered only cases wherein each infectious disease was the primary diagnosis. Secondly, the practical classification of the infectious disease might not reflect the changes of disease epidemiology and specific public health measures for control and prevention including changes in vaccination coverage (1). For examples, influenza, hepatitis A and B are now recognized as diseases prevented by vaccination, but influenza is still classified as respiratory tract infection, and hepatitis A and B are still classified as viral hepatitis. Finally, as health care statistics of HIRA was used to estimate the cost of infectious disease, this study could not identify detailed cost categories. Further research that consider age groups and costs by socio-economic status, regions and service category; medication or prescription, doctor's fee, admission charge, etc. is needed to set priorities for effective strategies of infectious disease control and prevention.

In conclusion, the mortality trends (1997-2019) and costs (2009-2019) of infectious disease in Korea have increased. In particular, respiratory tract infections are needed to pay much attention in disease control, considering high mortality rate in elderly persons with respiratory tract infections and the biggest medical expenses for treating them among the other expenses of 10 diseases groups. Therefore, effective policy and efficient management by each disease group are needed to reduce the burden of infectious disease based on this study results. Moreover, this study is particularly important reference for identifying the long-term trends including mortality, outbreak, financial burden of infectious disease in Korea before COVID-19 outbreak.

\section{Conflicts of interest}

The authors have no conflicts of interest to declare for this study.

\section{Author contributions}

Conceptualization: MK. Data curation: DB, BWK. Formal analysis \& Writing: DB.

\section{References}


1. Choe YJ, Choe SA, Cho SI. Trends in Infectious Disease Mortality, South Korea, 1983-2015. Emerg Infect Dis. 2018;24(2):320-7. Epub 2018/01/20. doi: 10.3201/eid2402.170862. PubMed PMID: 29350153; PubMed Central PMCID: PMCPMC5782883.

2. Mortality GBD, Causes of Death C. Global, regional, and national life expectancy, all-cause mortality, and cause-specific mortality for 249 causes of death, 1980-2015: a systematic analysis for the Global Burden of Disease Study 2015. Lancet. 2016;388(10053):1459-544. Epub 2016/10/14. doi: 10.1016/S0140-6736(16)31012-1. PubMed PMID: 27733281; PubMed Central PMCID: PMCPMC5388903.

3. Death rate, crude [Internet]. [cited 2021 OCT 6]. Available from: http://data.worldbank.org/indicator/SP.DYN.CDRT.IN?locations=KR.

4. Life expectancy at birth, total [Internet]. [cited 2021 OCT 6]. Available from: http://data.worldbank.org/indicator/SP.DYN.LEO0.IN?location=KR.

5. Lee YR, Moon K, Kim YA, Park SY, Oh CM, Lee KS, et al. Disability-Adjusted Life Years for Communicable Disease in the Korean Burden of Disease Study 2012. J Korean Med Sci. 2016;31 Suppl 2:S178-S83. Epub 2016/10/25. doi: 10.3346/jkms.2016.31.S2.S178. PubMed PMID: 27775255; PubMed Central PMCID: PMCPMC5081299.

6. Jo C. Cost-of-illness studies: concepts, scopes, and methods. Clin Mol Hepatol. 2014;20(4):32737. Epub 2014/12/31. doi: 10.3350/cmh.2014.20.4.327. PubMed PMID: 25548737; PubMed Central PMCID: PMCPMC4278062.

7. Baik D, Kim BW, Oh JK, Kim KA, Ki M. Costs of viral hepatitis B in the Republic of Korea, 20022015. J Viral Hepat. 2020;27(2):156-67. Epub 2019/10/23. doi: 10.1111/jvh.13219. PubMed PMID: 31638305.

8. Yoo KH, Ahn HR, Park JK, Kim JW, Nam GH, Hong SK, et al. Burden of Respiratory Disease in Korea: An Observational Study on Allergic Rhinitis, Asthma, COPD, and Rhinosinusitis. Allergy Asthma Immunol Res. 2016;8(6):527-34. Epub 2016/09/02. doi: 10.4168/aair.2016.8.6.527. PubMed PMID: 27582404; PubMed Central PMCID: PMCPMC5011053.

9. Kim HS, Eun SJ. Age-Period-Cohort Analysis of Trends in Infectious Disease Mortality in South Korea from 1983 to 2017. Int J Environ Res Public Health. 2021;18(3). Epub 2021/01/27. doi: 10.3390/ijerph18030906. PubMed PMID: 33494300; PubMed Central PMCID: PMCPMC7908575. 10. Kim HK, Song SO, Noh J, Jeong IK, Lee BW. Data Configuration and Publication Trends for the Korean National Health Insurance and Health Insurance Review \& Assessment Database. Diabetes Metab J. 2020;44(5):671-8. Epub 2020/10/30. doi: 10.4093/dmj.2020.0207. PubMed PMID: 33115211; PubMed Central PMCID: PMCPMC7643590.

11. Cheol Seong S, Kim YY, Khang YH, Heon Park J, Kang HJ, Lee H, et al. Data Resource Profile: The National Health Information Database of the National Health Insurance Service in South Korea. Int J Epidemiol. 2017;46(3):799-800. Epub 2016/10/31. doi: 10.1093/ije/dyw253. PubMed PMID: 27794523; PubMed Central PMCID: PMCPMC5837262.

12. Joinpoint Regression Program. 4.8.0.1 ed. National Cancer Institute: Statistical Research and Applications Branch; April, 2020. 
13. Foreign Exchange Rate [Internet]. Bank of Korea 「https://ecos.bok.or.kr」 2021. 8, IMF $\ulcorner$ International Financial Statistics」2021. 7. [cited 2021 OCT 6]. Available from:

https://kosis.kr/statHtml/statHtml.do?orgId=101\&tblId=DT_2KAA811\&conn_path=I3.

14. Consumer Price Index by Item [Internet]. Statistics Korea. [cited 2021 OCT 6]. Available from: https://kosis.kr/statHtml/statHtml.do?orgId=101\&tblId=DT_1J17001\&conn_path=I2.

15. Global tuberculosis report 2019. Geneva: World Health Organization, 17 October 2019.

16. National Health Insurance Statistical Yearbook 2020. Health Insurance Review and Assessment Service, Natioal Health Insurance Service; October, 2020 
Table1. Selection of infectious disease group using the international statistical classification of disease and related health problems 10th revision [ICD-10] codes

\begin{tabular}{ll}
\hline \multicolumn{1}{c}{ Group } & \multicolumn{1}{c}{ ICD-10 codes } \\
\hline All infectious disease & A00-B99, G00-G09, I00-I09, J00-06, J09-J18, J20-J22, \\
J85-J86, L00-L08, M86, N10-N12, N70-N77, P35-P39
\end{tabular}


Table2. The number of patients and the cost of infectious disease in the Republic of Korea, 2009-2019

\begin{tabular}{|c|c|c|c|c|c|c|c|c|c|c|c|c|c|c|}
\hline \multirow[b]{2}{*}{ Year } & \multirow[b]{2}{*}{$\begin{array}{l}\text { No. } \\
\text { of } \\
\text { patients } \\
\text { (persons) }\end{array}$} & \multicolumn{5}{|c|}{ Inpatient } & \multicolumn{5}{|c|}{ Outpatient } & \multirow[b]{2}{*}{$\begin{array}{l}\text { Total } \\
\text { cost } \\
\text { (million } \\
\text { USD) }\end{array}$} & \multirow[b]{2}{*}{$\begin{array}{c}\text { Cost } \\
\text { per } \\
\text { Patient }{ }^{2} \\
(\text { USD) }\end{array}$} & \multirow[b]{2}{*}{$\begin{array}{c}\text { Inflation } \\
\text { adjusted } \\
\text { total } \\
\text { cost }^{3} \\
\text { (million } \\
\text { USD) }\end{array}$} \\
\hline & & $\begin{array}{c}\text { No. } \\
\text { of } \\
\text { patients } \\
\text { (persons) }\end{array}$ & $\begin{array}{c}\text { Days of } \\
\text { hospitalization } \\
\text { (Days) }\end{array}$ & $\begin{array}{c}\text { Average days } \\
\text { of } \\
\text { hospitalization } \\
\text { (Days/per person) }\end{array}$ & $\begin{array}{l}\text { Cost } \\
\text { (million } \\
\text { USD }{ }^{1} \text { ) }\end{array}$ & $\begin{array}{c}\text { Average } \\
\text { cost per } \\
\text { patient } \\
\text { (USD) }\end{array}$ & $\begin{array}{l}\text { No. of } \\
\text { patients } \\
\text { (persons) }\end{array}$ & $\begin{array}{c}\text { Days of visit } \\
\text { (Days) }\end{array}$ & $\begin{array}{c}\text { Average } \\
\text { days } \\
\text { of } \\
\text { visit } \\
\text { (Days/per } \\
\text { person) }\end{array}$ & $\begin{array}{l}\text { Cost } \\
\text { (million } \\
\text { USD) }\end{array}$ & $\begin{array}{l}\text { Average } \\
\text { cost per } \\
\text { patient } \\
\text { (USD) }\end{array}$ & & & \\
\hline 2009 & $31,570,316$ & 870,586 & $8,338,531$ & 9.6 & 922 & 1,059 & $31,481,267$ & $168,665,913$ & 5.4 & 3,204 & 102 & 4,126 & 131 & 4,412 \\
\hline 2010 & $31,286,710$ & 943,115 & $9,068,217$ & 9.6 & 1,026 & 1,088 & $31,190,895$ & $170,266,963$ & 5.5 & 3,205 & 103 & 4,231 & 135 & 4,446 \\
\hline 2011 & $31,056,053$ & 977,903 & $9,340,405$ & 9.6 & 1,092 & 1,117 & $30,718,861$ & $165,983,722$ & 5.4 & 3,232 & 105 & 4,325 & 139 & 4,466 \\
\hline 2012 & $31,733,206$ & $1,038,167$ & $9,727,210$ & 9.4 & 1,154 & 1,111 & $31,629,989$ & $171,376,085$ & 5.4 & 3,275 & 104 & 4,429 & 140 & 4,532 \\
\hline 2013 & $31,508,376$ & $1,027,771$ & $9,666,999$ & 9.4 & 1,178 & 1,147 & $31,399,997$ & $167,566,340$ & 5.3 & 3,314 & 106 & 4,492 & 143 & 4,581 \\
\hline 2014 & $32,485,239$ & $1,123,732$ & $10,315,378$ & 9.2 & 1,302 & 1,159 & $32,371,607$ & $173,371,141$ & 5.4 & 3,576 & 110 & 4,878 & 150 & 4,939 \\
\hline 2015 & $32,069,591$ & $1,211,936$ & $11,047,023$ & 9.1 & 1,510 & 1,246 & $31,944,506$ & $166,382,056$ & 5.2 & 3,631 & 114 & 5,141 & 160 & 5,141 \\
\hline 2016 & $33,082,602$ & $1,506,536$ & $11,964,776$ & 7.9 & 1,742 & 1,156 & $32,927,734$ & $176,992,342$ & 5.4 & 4,078 & 124 & 5,820 & 176 & 5,763 \\
\hline 2017 & $32,571,529$ & $1,349,999$ & $11,124,243$ & 8.2 & 1,785 & 1,322 & $32,411,697$ & $167,472,742$ & 5.2 & 4,054 & 125 & 5,840 & 179 & 5,732 \\
\hline 2018 & $33,416,385$ & $1,437,389$ & $11,846,714$ & 8.2 & 2,090 & 1,454 & $33,249,884$ & $171,840,247$ & 5.2 & 4,348 & 131 & 6,438 & 193 & 6,322 \\
\hline 2019 & $32,374,393$ & $1,386,980$ & $11,677,868$ & 8.4 & 2,278 & 1,643 & $32,210,573$ & $164,638,317$ & 5.1 & 4,334 & 135 & 6,612 & 204 & 6,464 \\
\hline
\end{tabular}

1USD: United States dollar (1 USD = 1136.7 Korean won; average exchange rate from 2009 to 2019).

${ }^{2}$ Cost per patient $=$ Total cost of the 2009-2019 period / number of patients who received treatment for infectious disease in the $2009-2019$ period.

${ }^{3}$ Inflation adjusted costs were adjusted using consumer price index in $2015^{14}$. 


\section{Figure Legends}

Figure1. Age-standardized mortality rate (1997-2019) and prevalence rate (2009-2019) of infectious disease

Figure2. Age-standardized mortality rate of infectious disease by 10 selected groups in Republic of Korea, 1997-2019

Figure3. Age-specific mortality rate of respiratory tract infection in Republic of Korea, 1997-2019

Figure4. The trend of healthcare cost for infectious disease in Republic of Korea, 2009-2019

Figure5. Cost of infectious disease by 10 selected groups in Republic of Korea, 2009-2019 
Table1. Selection of infectious disease group using the international statistical classification of disease and related health problems 10th revision [ICD-10] codes

\begin{tabular}{ll}
\hline \multicolumn{1}{c}{ Group } & \multicolumn{1}{c}{ ICD-10 codes } \\
\hline All infectious disease & A00-B99, G00-G09, I00-I09, J00-06, J09-J18, J20-J22, \\
J85-J86, L00-L08, M86, N10-N12, N70-N77, P35-P39
\end{tabular}


Table2. The number of patients and the cost of infectious disease in the Republic of Korea, 2009-2019

\begin{tabular}{|c|c|c|c|c|c|c|c|c|c|c|c|c|c|c|}
\hline \multirow[b]{2}{*}{ Year } & \multirow[b]{2}{*}{$\begin{array}{c}\text { No. } \\
\text { of } \\
\text { patients } \\
\text { (persons) }\end{array}$} & \multicolumn{5}{|c|}{ Inpatient } & \multicolumn{5}{|c|}{ Outpatient } & \multirow[b]{2}{*}{$\begin{array}{l}\text { Total } \\
\text { cost } \\
\text { (million } \\
\text { USD) }\end{array}$} & \multirow[b]{2}{*}{$\begin{array}{c}\text { Cost } \\
\text { per } \\
\text { Patient } \\
\text { Pas } \\
\text { (USD) }\end{array}$} & \multirow[b]{2}{*}{$\begin{array}{c}\text { Inflation } \\
\text { adjusted } \\
\text { total } \\
\text { cost }^{3} \\
\text { (million } \\
\text { USD) }\end{array}$} \\
\hline & & $\begin{array}{c}\text { No. } \\
\text { of } \\
\text { patients } \\
\text { (persons) }\end{array}$ & $\begin{array}{c}\text { Days of } \\
\text { hospitalization } \\
\text { (Days) }\end{array}$ & $\begin{array}{c}\text { Average days } \\
\text { of } \\
\text { hospitalization } \\
\text { (Days/per person) }\end{array}$ & $\begin{array}{l}\text { Cost } \\
\text { (million } \\
\text { USD }^{1} \text { ) }\end{array}$ & $\begin{array}{l}\text { Average } \\
\text { cost per } \\
\text { patient } \\
\text { (USD) }\end{array}$ & $\begin{array}{l}\text { No. of } \\
\text { patients } \\
\text { (persons) }\end{array}$ & $\begin{array}{c}\text { Days of visit } \\
\text { (Days) }\end{array}$ & $\begin{array}{l}\text { Average } \\
\text { days } \\
\text { of } \\
\text { visit } \\
\text { (Days/per } \\
\text { person) }\end{array}$ & $\begin{array}{l}\text { Cost } \\
\text { (million } \\
\text { USD) }\end{array}$ & $\begin{array}{l}\text { Average } \\
\text { cost per } \\
\text { patient } \\
\text { (USD) }\end{array}$ & & & \\
\hline 2009 & $31,570,316$ & 870,586 & $8,338,531$ & 9.6 & 922 & 1,059 & $31,481,267$ & $168,665,913$ & 5.4 & 3,204 & 102 & 4,126 & 131 & 4,412 \\
\hline 2010 & $31,286,710$ & 943,115 & $9,068,217$ & 9.6 & 1,026 & 1,088 & $31,190,895$ & $170,266,963$ & 5.5 & 3,205 & 103 & 4,231 & 135 & 4,446 \\
\hline 2011 & $31,056,053$ & 977,903 & $9,340,405$ & 9.6 & 1,092 & 1,117 & $30,718,861$ & $165,983,722$ & 5.4 & 3,232 & 105 & 4,325 & 139 & 4,466 \\
\hline 2012 & $31,733,206$ & $1,038,167$ & $9,727,210$ & 9.4 & 1,154 & 1,111 & $31,629,989$ & $171,376,085$ & 5.4 & 3,275 & 104 & 4,429 & 140 & 4,532 \\
\hline 2013 & $31,508,376$ & $1,027,771$ & $9,666,999$ & 9.4 & 1,178 & 1,147 & $31,399,997$ & $167,566,340$ & 5.3 & 3,314 & 106 & 4,492 & 143 & 4,581 \\
\hline 2014 & $32,485,239$ & $1,123,732$ & $10,315,378$ & 9.2 & 1,302 & 1,159 & $32,371,607$ & $173,371,141$ & 5.4 & 3,576 & 110 & 4,878 & 150 & 4,939 \\
\hline 2015 & $32,069,591$ & $1,211,936$ & $11,047,023$ & 9.1 & 1,510 & 1,246 & $31,944,506$ & $166,382,056$ & 5.2 & 3,631 & 114 & 5,141 & 160 & 5,141 \\
\hline 2016 & $33,082,602$ & $1,506,536$ & $11,964,776$ & 7.9 & 1,742 & 1,156 & $32,927,734$ & $176,992,342$ & 5.4 & 4,078 & 124 & 5,820 & 176 & 5,763 \\
\hline 2017 & $32,571,529$ & $1,349,999$ & $11,124,243$ & 8.2 & 1,785 & 1,322 & $32,411,697$ & $167,472,742$ & 5.2 & 4,054 & 125 & 5,840 & 179 & 5,732 \\
\hline 2018 & $33,416,385$ & $1,437,389$ & $11,846,714$ & 8.2 & 2,090 & 1,454 & $33,249,884$ & $171,840,247$ & 5.2 & 4,348 & 131 & 6,438 & 193 & 6,322 \\
\hline 2019 & $32,374,393$ & $1,386,980$ & $11,677,868$ & 8.4 & 2,278 & 1,643 & $32,210,573$ & $164,638,317$ & 5.1 & 4,334 & 135 & 6,612 & 204 & 6,464 \\
\hline
\end{tabular}

1USD: United States dollar (1 USD = 1136.7 Korean won; average exchange rate from 2009 to 2019).

${ }^{2}$ Cost per patient $=$ Total cost of the 2009-2019 period / number of patients who received treatment for infectious disease in the $2009-2019$ period.

${ }^{3}$ Inflation adjusted costs were adjusted using consumer price index in $2015^{14}$. 


\section{Figure1. Age-standardized mortality rate (1997-2019) and prevalence rate (2009-2019) of infectious disease in Republic of Korea}

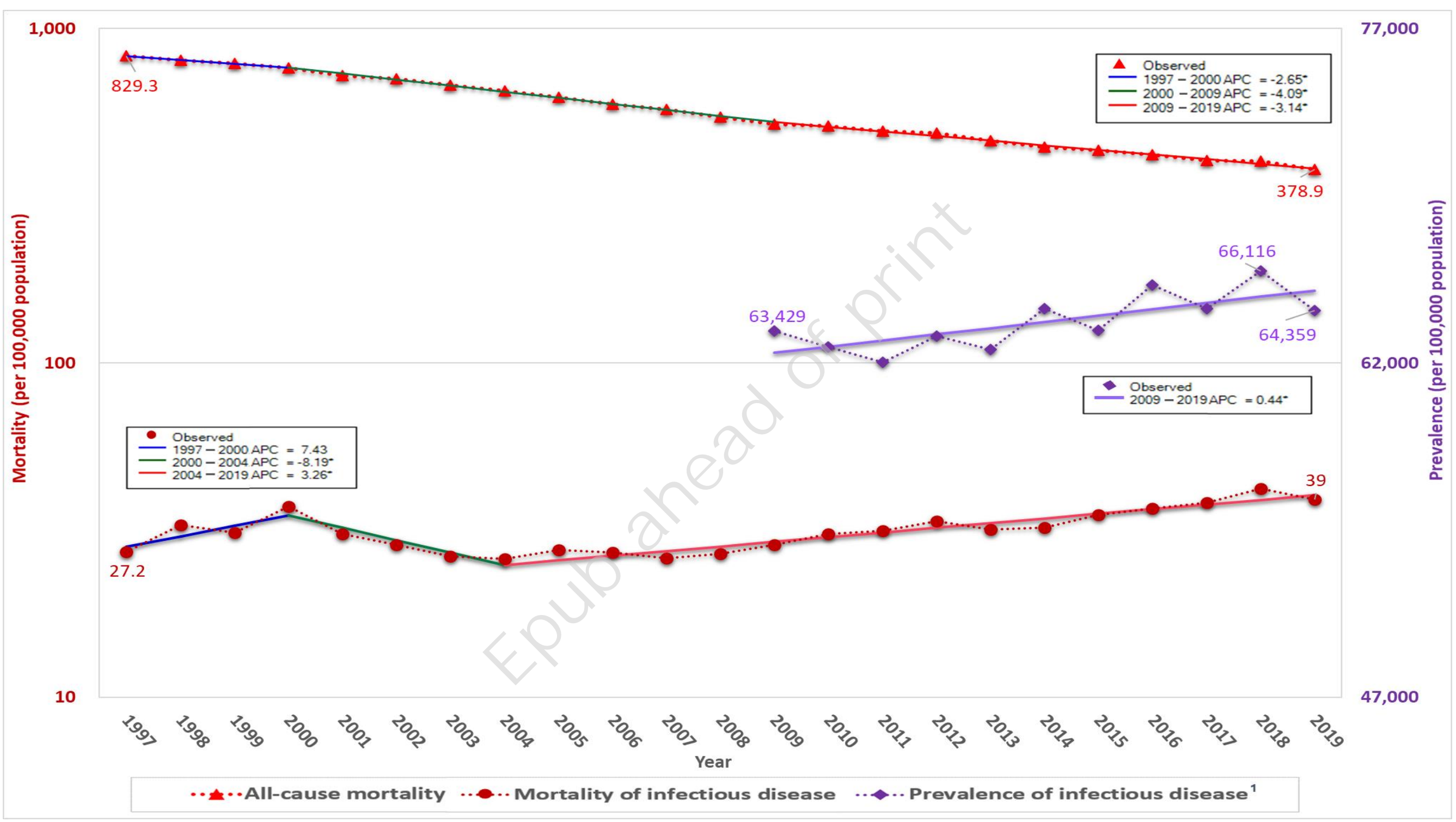

1Prevalence of infectious disease was considered as the annual total number of patients who were treated for infectious disease. It was adjusted using registered population data in 2010.

* indicates that APC is significantly different from zero at the alpha $=0.05$ level. 
Figure. Age-standardized mortality rate of infectious disease by 10 selected groups in Republic of Korea, 1997-2019

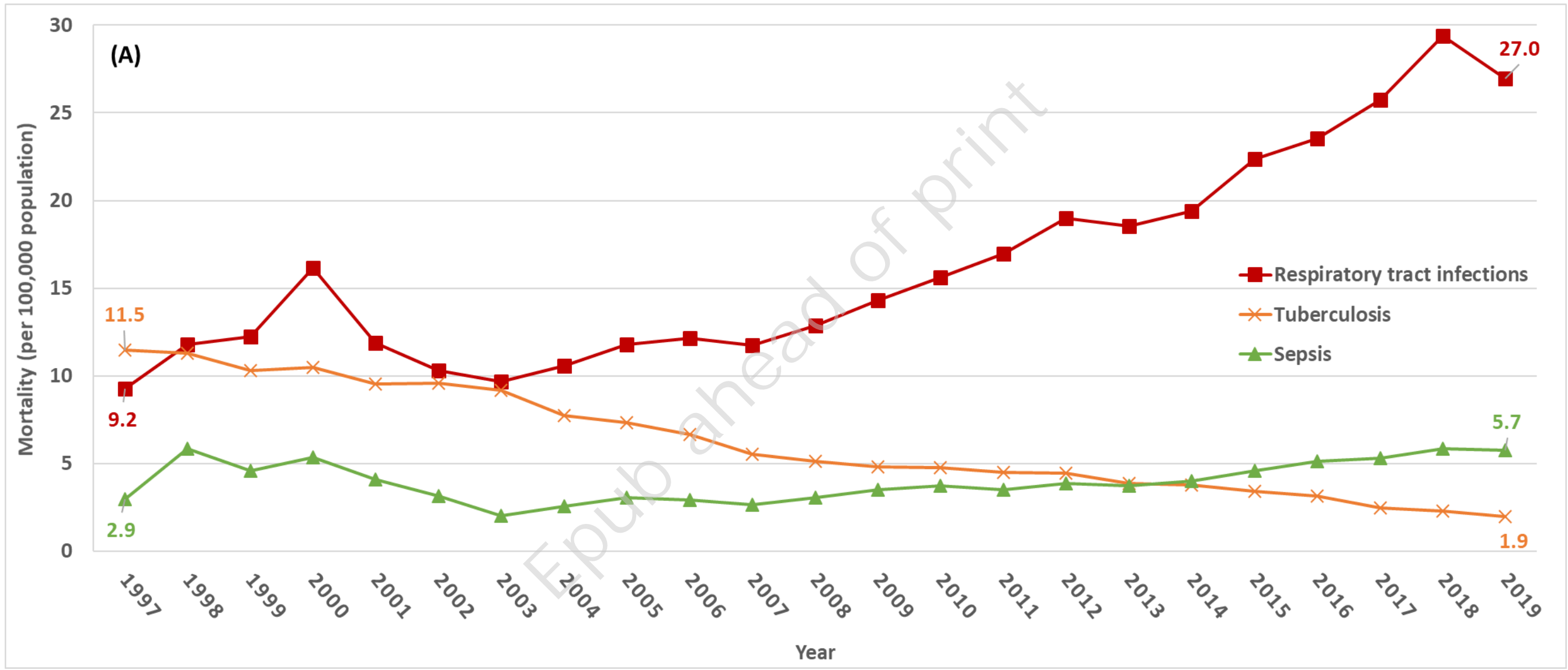




\section{(Continued)}

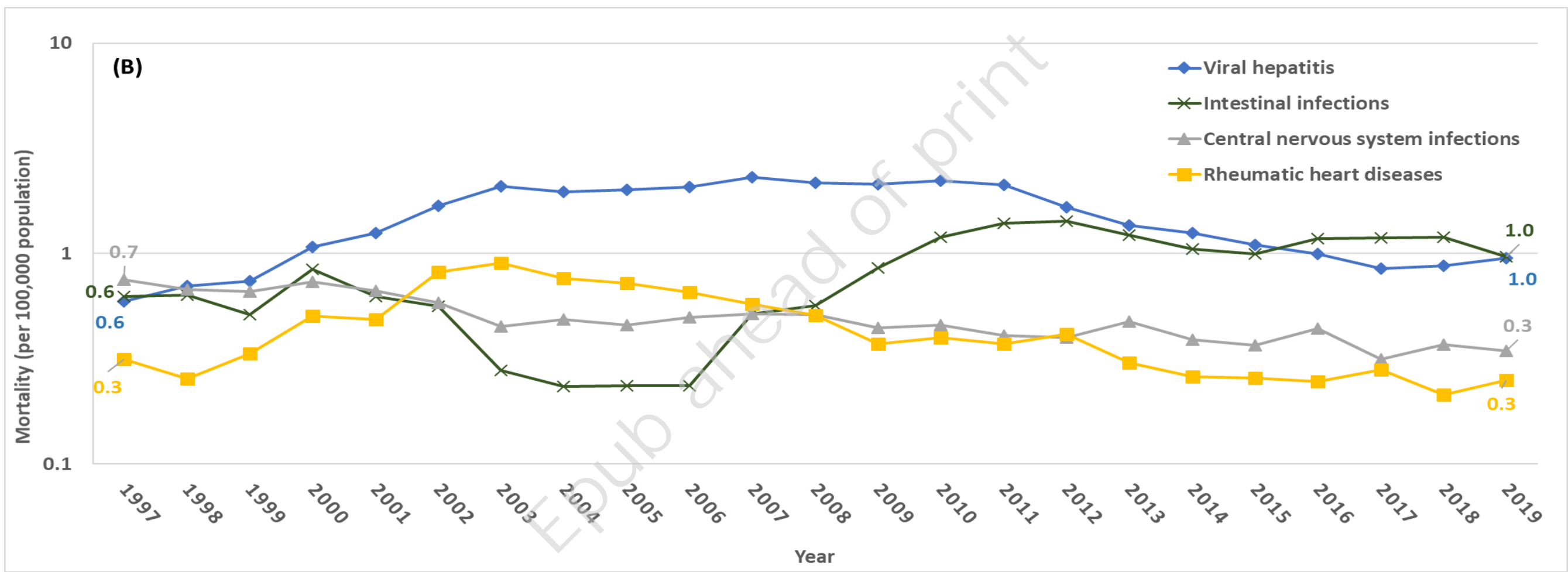


(Continued)

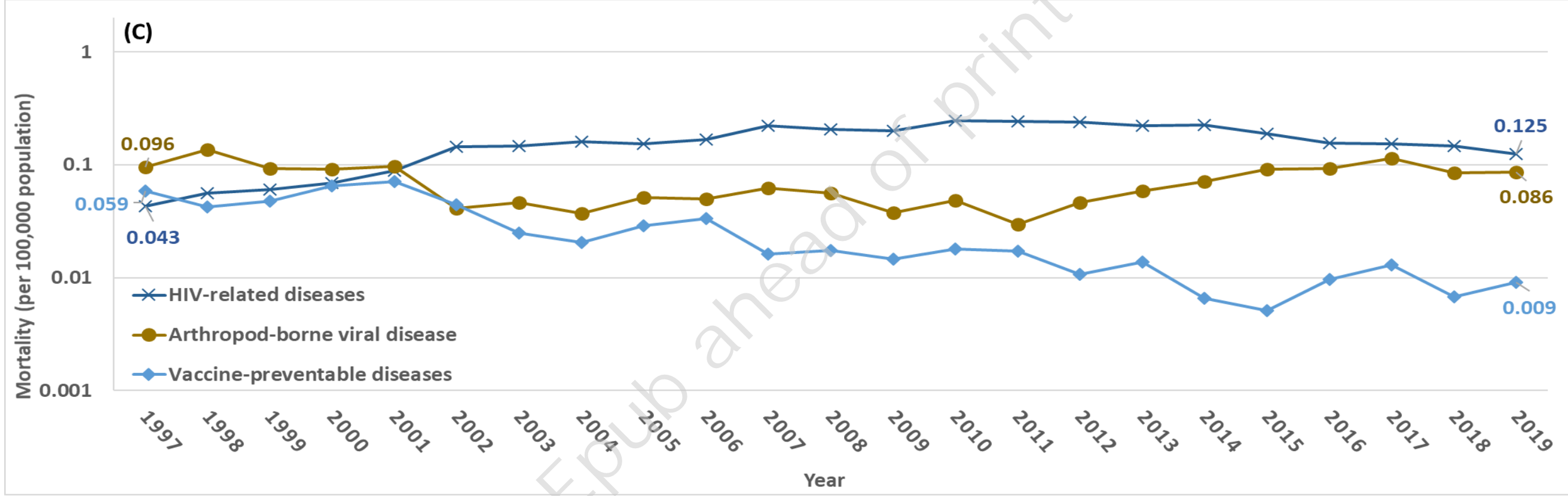




\section{Figure3. Age-specific mortality rate of respiratory tract infection in Republic of Korea, 1997-2019}

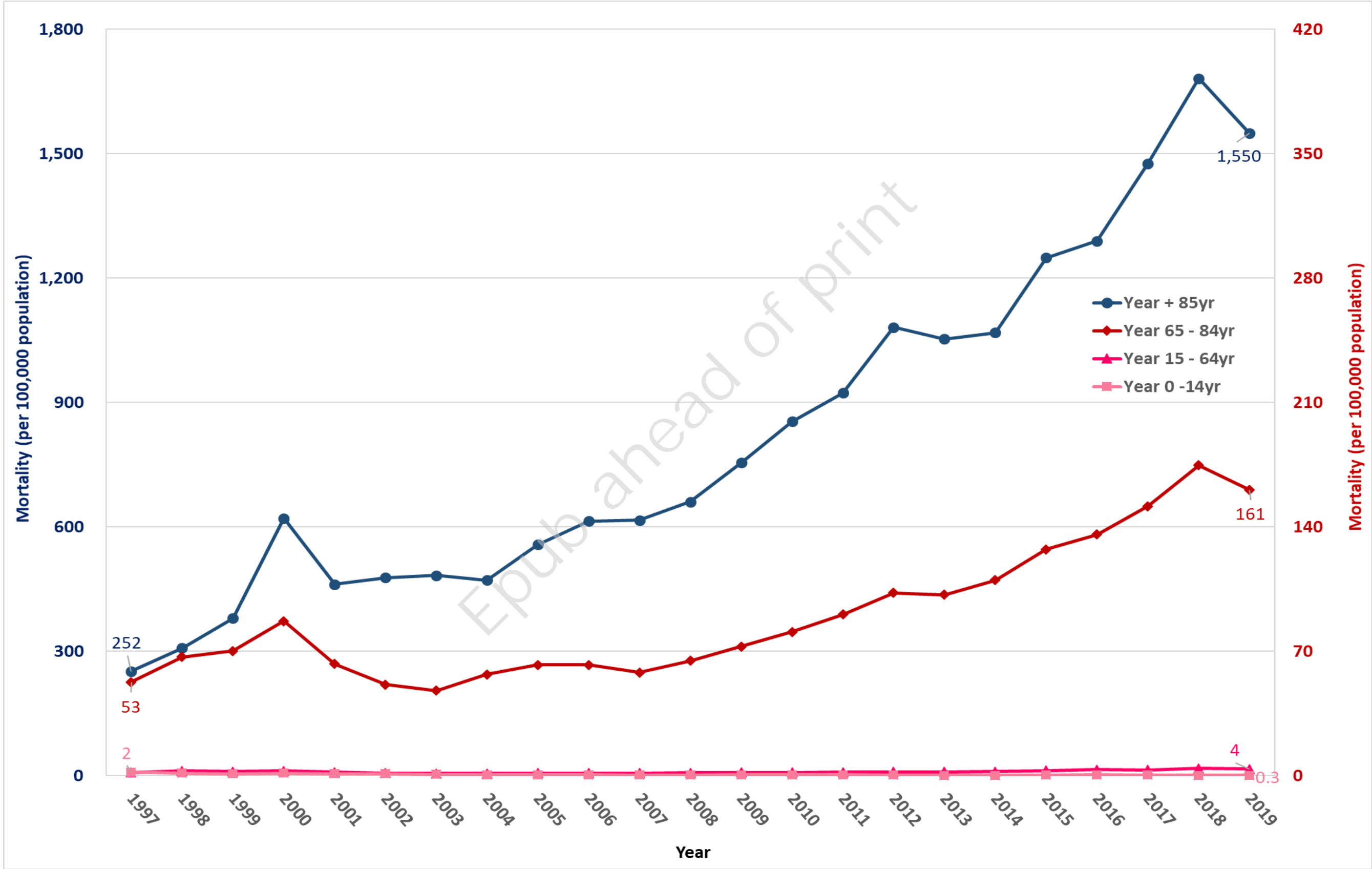


Figure4. The trend of healthcare cost for infectious disease in Republic of Korea, 2009-2019

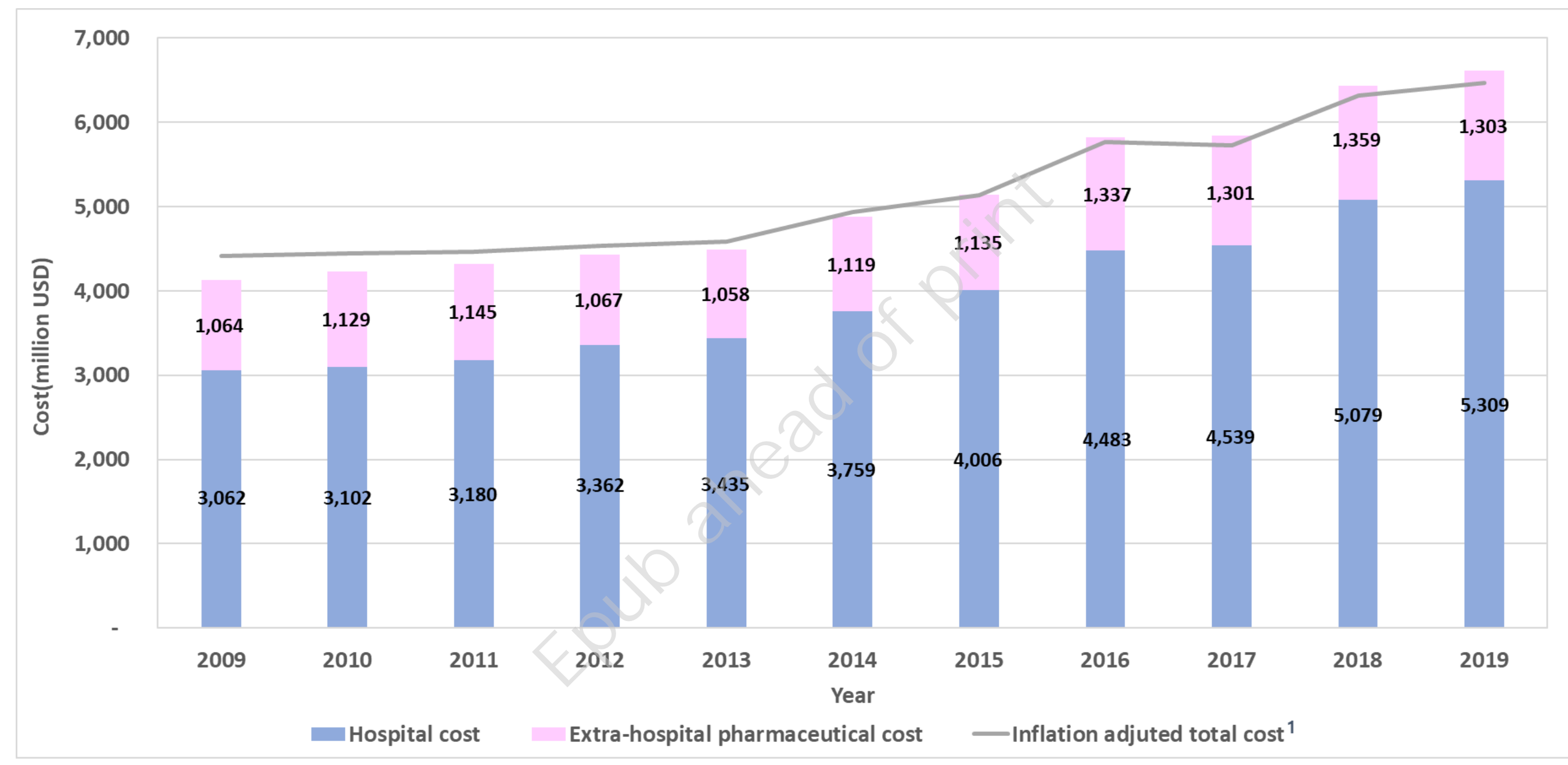

${ }^{1}$ Inflation adjusted costs were adjusted using consumer price index in $2015^{14}$. 


\section{Figure5. Cost of infectious disease by 10 selected groups in Republic of Korea, 2009-2019}

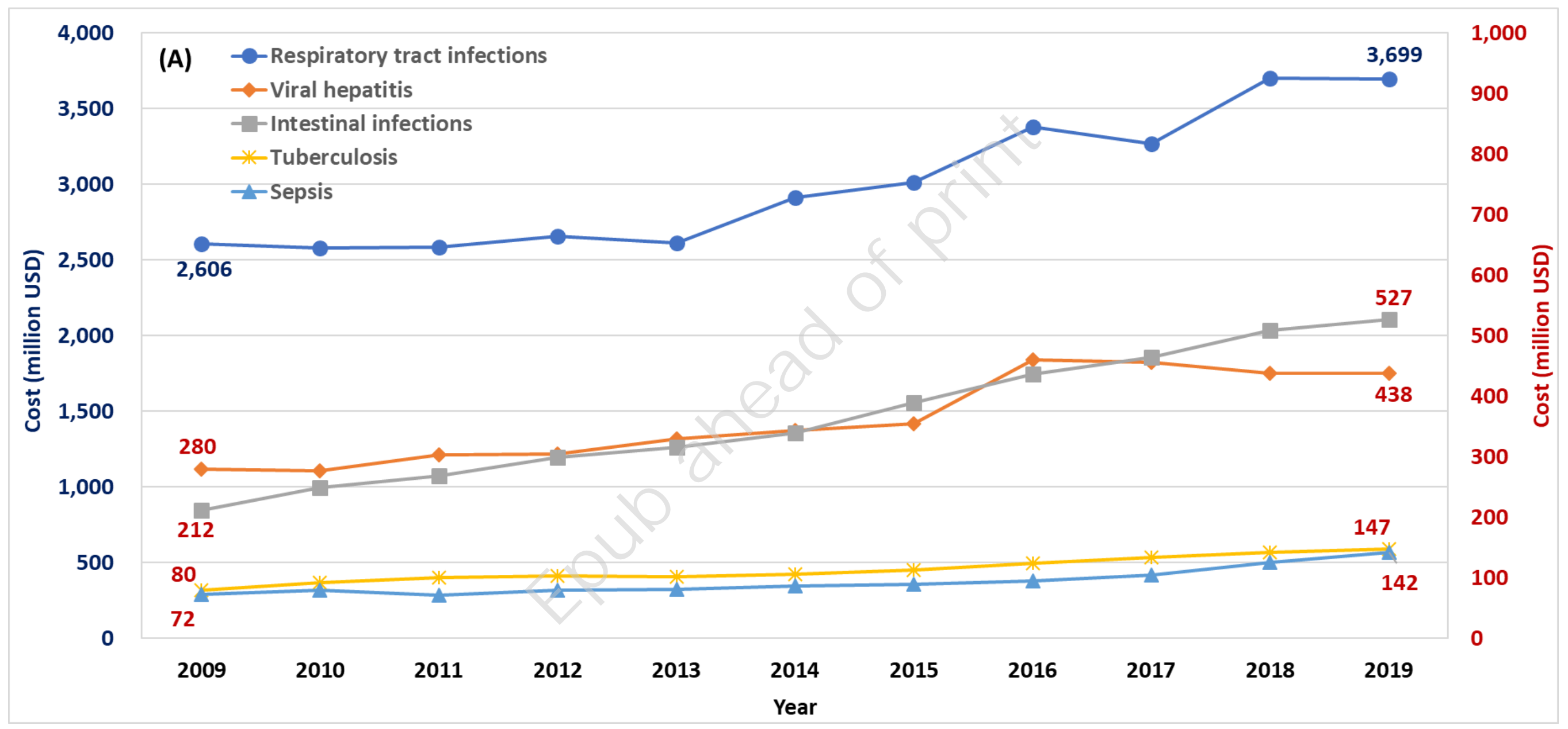




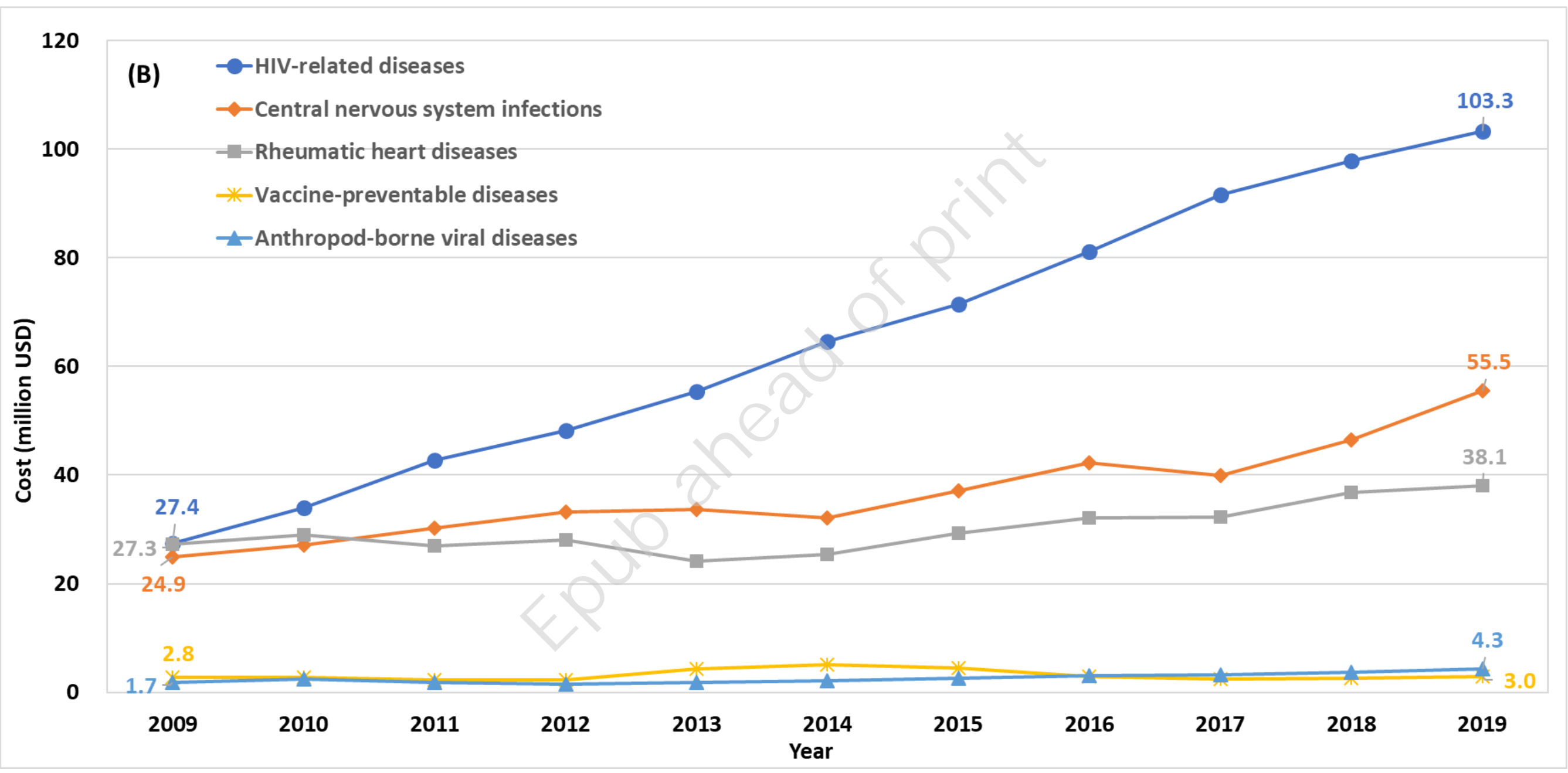

